\title{
Research on the Implementation of "Point-to-point" Rural Veterinary Clinic under Accurate Poverty Alleviation
}

\author{
—Build an integrated "Internet +" electronic platform \\ Qi Yu
}

Sichuan Agricultural University, Chengdu, Sichuan, 611130

\begin{abstract}
Keywords: Accurate Poverty Alleviation; Rural; Veterinary Clinic; Peer to Peer; Internet +
\end{abstract}
\begin{abstract}
Since the 18th CPC National Congress, remarkable achievements have been made in helping the poor and tackling hardships, and the gap between the rich and the poor has been further narrowed, thanks to the proposal of precise poverty alleviation policies. At the 19th CPC National Congress, socialism with Chinese characteristics entered a new era, and poverty alleviation and development work also entered the spurt of "eating hard bones and tackling tough issues." The target of precision poverty alleviation is rural farmers, but with the further deepening of poverty alleviation work, farmers are subjectively unwilling to be out of poverty, and the objective problems of lack of farming techniques and sales channels are gradually exposed. In order to solve these emerging problems in the process of precision poverty alleviation, we propose a strategy of using the Internet + background to build an integrated electronic platform. By injecting funds to farmers, providing veterinary diagnosis and treatment technologies and sales platforms, the Bank will implement a "peer-to-peer" model of innovative poverty alleviation and make full use of social resources to achieve the effect of highly integrated resources. In the end, it will help promote poverty alleviation while benefiting from multiple sources.
\end{abstract}

\section{Introduction}

At the 19th of October this year, the 18th National Congress of the Communist Party of China held in Beijing. General Secretary Xi Jinping reviewed the work done in the past 19 years in the past 19 years and said: "The decisive progress in fighting off poverty has achieved decisive progress. More than 60 million poor people have steadily escaped poverty. The incidence of poverty has dropped from $10.2 \%$ dropped to below $4 \%$, the gap between rich and poor was further narrowed, and socialism with Chinese characteristics entered a new era. Looking back, the remarkable achievements of the anti-poverty work have been attributed to the precise poverty alleviation policy put forward by the CPC. With achievements of more than 13 million people each year, China has written the "greatest story" in the history of human struggle against poverty and won the trust of the international community Highly praised.

The earliest proposal of "precise poverty alleviation" was made in November 2013 when Xi Jinping visited Hunan and Hunan Province for the first time and made an important directive of "seeking truth from facts, adjusting measures to local conditions, guiding classified sources and helping the poor precisely." General Secretary Xi indicated that the core content is mainly to repair and improve the existing system and mechanism of poverty alleviation so as to have stronger practice orientation and system pertinence. In other words, it is necessary to refine the solution to the problem of who to use money and policies, how to use it and how to spend it. Its core is "precision", that is, "accurate targets for poverty alleviation, precise arrangement of projects, precise use of funds, accurate implementation of measures by households, precision by village dispatch, and precision in poverty reduction." It has transformed the broad-based mentality of helping the poor and removed from the "irrigation-type" and "blood-transfusion" model of poverty alleviation. Demands for helping the poor to do a real job [1], so that poverty alleviation really help the poor.

Nearly 40 years of reform and opening up have brought hundreds of millions of Chinese people out of poverty, but China's poverty alleviation work still faces many difficulties. According to the 
latest statistics, as of the end of 2016, there were 43.35 million rural poor people. This shows that the lagging development in poverty-stricken areas still exists and is acute. There is a very arduous task in tackling the problem of poverty. The greater the difficulty of getting out of poverty later, as most of the remaining areas and masses are in poorer conditions, weaker bases and deeper poverty. We should take the areas with deep poverty as key areas for tackling the problem and increase the intensity and depth of poverty alleviation so as to ensure that the tasks of getting rid of the poverty problem at the established time are completed. At present, there has been no fundamental change in the development lagging behind in poor areas in our country. In the people's livelihood issues, the disadvantaged groups tend to have more and stronger demands and therefore need more attention and assistance so as to further refine the poverty alleviation work.

$\mathrm{Xi}$ Jinping pointed out that poverty alleviation and development work has entered a spurt of "eating hard bones, tackling tough issues". In areas with relatively underdeveloped poverty-stricken areas such as the southwest, the number of free-range animals in rural areas accounts for more than $60 \%$ of the total market supply. Although the demand for free-range animals in the market is relatively high, the incomes are low Therefore, it is the "hard bones" that scattered recuperating households are the key poverty alleviation targets of the country. The reason for the "hard bones" is that on the one hand, the sub-initiative of the peasants themselves in getting out of poverty is not strong; on the other hand, the problems existing in the livestock breeding chain of the scattered-reeducation households are exasperated.

\section{The "bones hard" subjective aspects}

As the work on poverty alleviation has been further carried out and further deepened, the policy has become more precise, a stumbling block to the three major poverty alleviation efforts has emerged, and the smooth progress of poverty alleviation work has been seriously hampered.

\subsection{The lack of enthusiasm for getting rid of poverty depends on the seriousness of thinking}

Some so-called "poor households" formed lucky ones and relied too much on poverty alleviation funds. They are subjectively reluctant to get out of poverty and gradually lead to the "negative collective encouragement of poor people" to improve their livelihoods due to the lack of efforts to alleviate poverty [2] In the subjective sense, they did not actively develop aquaculture production. Nor did they have the positive thinking of standardizing and scaling up aquaculture, greatly restricting the pace of informal supportive farming towards formalized aquaculture.

\subsection{The allocation of poverty alleviation fund is irrational, and the assessment criteria need to be strengthened}

In poverty alleviation process, the gradual emergence of differentiation due to the different levels of poverty, that is, the poverty caused by various reasons of their own families, some peasants have long been in poverty because they have not been given enough help. For "real" poor households, they have no absolute competitive advantage because of "low starting line", and the absolute gap between them with different rural households in the region has been constantly increasing. These structural peasants are marginalized because of their low incomes and lack of living capacity to consume. They are despised by their neighborhoods and lack the right to speak in the villages.

\subsection{Poverty alleviation and "resilience" are weak and prone to return to poverty}

While the gap between the rich and the poor is narrowing and the peasants' living conditions are improving day by day, the concept of living consumption of peasants has undergone tremendous changes due to the impact of the market and the increase in population flow. Comparisons between the peasants and the peasants have shown signs of competition and competition, with less accumulated consumption and no More funds for expanding the scale of production, so can not withstand the "man-made disaster" blow, easy to cause "return to poverty" [3]. 


\section{Objective aspects}

For many rural farmers, veterinary diagnosis and treatment technology in breeding process is a real threshold. The lack of breeding techniques and improper prevention and treatment of diseases have brought tremendous difficulties to breeding work.

\section{1 feeding preparation}

\subsubsection{Selection and planning of breeding structure}

When buying young animals and feed, farmers give priority to prices. Young animals purchased at low prices are often poorly developed, with poor physical fitness, susceptible to illness and high mortality rates, and the irrational selection of species shows two extreme phenomena of "single" and "mixed". Poor feed quality of livestock and poultry, a single structure, nutrition with improper.

\subsubsection{Planning of feeding environment}

Inadequate infrastructure for breeding, poor housing environment, poor farming conditions, a pens animal too dense, together with the temperature, humidity and other changes with the environment, livestock and poultry so seasonal changes affect the large, stress and long-term life Discomfort makes it slow to grow. Furthermore, the lack of awareness of disinfection farmers, often only in the outbreak of livestock and poultry were eliminated or slaughtered after disinfection, disinfection has not been done regularly, and even some farmers rarely clean the barn. Bacteria and other microorganisms easily breed and lead to increased incidence of livestock and poultry.

\subsubsection{Garbage disposal}

Farmers do not attach importance to environmental protection issues, there is no reasonable standardization of harmless processing system or meet the requirements of the relevant standards, face the risk of demolition.

The inadequate preparation for the early stage of aquaculture hindered the development of decentralized households in rural areas towards regularization and large-scale aquaculture from the root causes.

\subsection{Raising the mid-term preparation}

\subsubsection{Vaccination}

Farmers lack of specialized expertise and knowledge reserves, weak epidemic prevention concepts, strong traditional concepts of "treating diseases without disease" and only vaccinating against the requirements of animal epidemic prevention departments, and some even refusing vaccinations. Even if the purchase of vaccines only pay attention to compare the price, immutable immutable lack of a certain scientific nature of the program, not according to the local epidemic and the health status of livestock and poultry in a timely manner to adjust the immune agent at random, immunological methods are free to change.

\subsection{2 feeding water}

Farmers use the traditional feeding methods, different types of livestock and poultry to feed, concentrate on feeding, ignoring the animal's habits and feeding habits and nutritional needs differences, a variety of animal interactions affect each other cross-infection. What their own production season, what to eat animals, feeding time, random amount of material, ignoring the growth of livestock and poultry nutrients required, leading to animal malnutrition, slow growth and low resistance and susceptibility to illness. Some free-range animals poisoned poisonous plants and poisoning, such as moldy sweet potato suffering from "black spot disease" or consumption of fresh grass magnesium poisoning. Sometimes due to negligence, mildew or expired feed improperly stored, farmers in order to save costs and do not understand the harmful substances produced by mildew, still make do with livestock and poultry, which greatly affect the health of animals and even cause poisoning. 


\subsubsection{The diagnosis and treatment response to the outbreak}

Encounter the sickness of livestock and poultry, farmers adhere to the concept of "sick before treatment" and only use subjective consciousness and traditional experience to treat them. There are four serious problems of medication, with "medicine is not right", "compatibility is unknown," "dose is not allowed" and "random treatment." Free medication lead to the disease did not improve or even spread, farmers see the loss will be even more serious anxious illness urgent investment, they increase the dosage or mixed with a variety of drugs to use, so that self-defeating, leading to animal drug poisoning. Or to see the animals have been relaxed to be vigilant, in order to save money to stop medication, but the pathogen in animals is a certain incubation period, the root cause is not removed, there are still risks of onset.

Due to the lack of theoretical guidance in scientific breeding techniques in the aquaculture sector, the development of rural free-floating households objectively makes it difficult for them to grow.

\section{3 feeding the late preparation}

\subsubsection{Livestock slaughter time is too dependent on the market, selling or not selling up}

Affected by the market, raising livestock and poultry prices generally reluctant sellers and pressure bar phenomenon, waiting for the market higher prices, which to some extent prompted the market prices, but once the peak price fell sharply across, farmers worry Resulting in greater losses, so the concentration of slaughter livestock appear selling tide. This phenomenon of slow sales led to "poor sales of top-grade goods," which prompted small-scale under-funded farmers to withdraw from aquaculture and further deepen poverty as a result of poor investment in aquaculture. Due to the influence of traditional customs in our country, there is a habitual consumption of Chinese New Year holidays. For example, before and after the traditional festival such as the Mid-Autumn Festival and the Spring Festival are the peak consumption of livestock and poultry. However, once the peak season is reached, the livestock and poultry market ushers in an off-season, this means that the new round of market prices, if the price fell more than the expectations of farmers or affordability, farmers will be out of the market, resulting in unsalable products.

\subsection{2 a single sales channel, funding difficulties return}

Farmers in rural areas have low direct slaughter rates because of their low slaughter rate and need to go through intermediaries 'acquisitions. The more intermediaries they deal with, the greater the loss of farmers' income. These intermediaries try hard to squeeze peasants for their own interests. The lowering of the purchase price has led to the fact that the peasants' income is not high even during the sales boom, which in turn makes it difficult for the funds to be repatriated and forms a vicious circle in the breeding chain.

The problems of slaughtering and marketing further increase the difficulty of farmers in rural areas so that they can not see the hope and prospect of developing breeding farms in rural areas. Therefore, the issue of developing farm culture in rural areas needs to be solved urgently.

\section{Respond to countermeasures}

To overcome "hard bones" we need to establish a more sound system of helping the poor and establish a more accurate standard of poverty alleviation. The author creatively put forward the "point to point" mode of poverty alleviation. This model not only can be accurate to every peasant household, but also facilitates the unified management, reduces manpower, material resources and unnecessary losses of poverty alleviation, makes full use of social resources and achieves the effect of highly integrated resources, and ultimately benefits multi-parties while ensuring the progress of anti-poverty work.

\section{1 "point to point" electronic platform construction:}

(1) Breeding households and investors docking: access to capital investment;

(2) farmer and college docking: get the veterinary diagnosis and treatment of colleges and 
universities technical support;

(3) docking with the buyer: access to sales channels to avoid unsalable products.

\section{2 the electronic platform constraints on the Quartet:}

(1) Farmers: build credibility assessment system to improve access standards;

(2) University: to ensure that colleges and universities provide all aspects of veterinary diagnosis and treatment technology;

(3) Investors: Strict review of investors, restrictions on the conditions of their nominee;

(4) Purchaser: supervision of the buyer timely payment, to avoid default.

Peer to Peer includes four "endpoints", namely, rural farmers, veterinary-related colleges and institutes, investors and purchasers. However, there is no clear link between these four main bodies. They are independent or have little contact with each other. In particular, the other three parties are not very concerned with the farmers who work for poverty alleviation. However, as an important target of poverty alleviation work, farmers need more More attention and help from all walks of life. In order to enhance the close contact between other three parties and farmers in rural areas, the author proposes to establish a third-party service platform as the "messenger" in the middle and serves as a bridge. The sponsoring department is preferably a government because it requires government advocacy and early capital investment, either through traditional means, such as going to the countryside and paper-based newspapers such as newspaper announcements, or through the Internet's electronic media such as creating official websites, Official microblogging, WeChat public number, etc. Through the construction of an electronic platform to provide PC-side and mobile APP, so that farmers can keep up to-date information and access to relevant information anytime, anywhere help.

At present, there has been an e-commerce service platform of "Internet + Agriculture" in the market, and the agricultural products are put on the network for sale, that is, the mode of "mouse + cabbage marketing", prompting the agricultural product marketing industry to be organically integrated with the Internet so that Agricultural products to achieve integrated sales service [4]. However, this new model of poverty alleviation only responds to the issue of marketing for farmers. There is no solution to the problem of farmers' capital injection in the early stage and the technical problems in breeding. In particular, it is to establish links between farmers and veterinary related colleges and institutes and institutions There is no fundamental solution to the problem of poor and dispersed farmers.

The author's conception of "peer-to-peer" mode using the Internet as its carrier is characterized by taking advantage of the advantages of the Internet, using the Internet as a platform and connecting the Internet and traditional industries through information technology to form a new model [5]. Accurately locate each farmer, real-time follow-up farmers information, so that each "end" communication between convenient and fast, in order to achieve a high degree of poverty alleviation work "accurate" to ensure that every poor households can get the appropriate help in order to achieve " Accurate out of poverty. "

\section{3 "point to point" platform for innovation}

\subsubsection{Precise identification, credit evaluation}

The establishment of a database of farmers' personal information as the main body will enable the farmers to track the multi-directional dynamic information and accurately evaluate their poverty and credit rating. Construction of third-party service platform, initiated by the government, investment and publicity. Hiring third parties to manage them and related professionals to develop mobile client and mobile APP, which are mainly used for the operation of the platform. Ancillary measures are to create a wider range of social publicity for official websites, Weibo and WeChat public account in order to improve Influence to attract more social attention. Mobile client and APP to establish a database, including rural family members of farmers structure, membership information, credit rating information, farming scale, the main problems and poverty levels and other information. Establish an all-round poverty identification system, organically combine the 
income ability, disposable power and spending power of peasant households, and identify more precisely and accurately which peasant households should be listed as poor households and give the corresponding funds and technologies Support. Similar to the current state of poor households to build file card information, but the current information there is a single identification standard, only rely on revenue to identify the file information lags and other issues. The advantages of this repository are meticulous, comprehensive, real-time, and efficient. The electronic platform aims to establish a credit rating and loan mechanism to provide small and medium-sized loans based on the reputation, reimbursement capacity and scale of farmers and to supervise the production and hygiene standards of farmers. The electronic platform is unqualified and does not want the rectifiers to cancel the loan qualifications, and organize the supervised information into the database. The database is shared with the other three parties, playing a transparent and comprehensive role in alleviating poverty. In addition to the information of farmers, when the other three parties register on the client side, the information investigation will be arranged and the four "endpoints" will know each other. The investigation of the information is entered into the field investigation conducted by the third party, namely, the client operator. It mainly refers to the information archiving of farmers in rural areas and the implementation of "contract system" to implement the tracking management of one individual against several farmers and update the database in real time. To solve the problem of poorly defined target groups and poor households unable to effectively help others.

\subsubsection{Resource counterparts, accurate help}

Resources to achieve "one to one" or "one to many" precise funding, taking into account the differences, special and systematic reality requirements. Resource investors, including large-scale farm enterprises and government funding for poverty alleviation, have solved the single source of precision poverty alleviation funding. At present, similar practices are already in place in China, such as the project of "family farms" pig breeding in Yangcheng County of the Wenceslas Group. This "company + farmer", "cooperative + farmer" funds to help practice has had a significant effect. Through this article "point to point" platform, mainly to solve the problem of the accuracy of the issue of funds. With the further development of poverty alleviation and fortification work, the standard of living of peasant households has been significantly improved. This change has not been reflected in the past project of establishing credit card cards. The updating of peasant household information lags behind and will result in some waste of funds for poverty alleviation. Therefore, the platform can update the synchronized information database in real time, and the investors can effectively provide one-on-one funding to ensure that the funds are used on the localities and effectively prevent farmers from "waiting, relying on, and wanting," "being proud of poverty and capable of poverty" Thinking, to some extent reduce the difficulty of helping the poor, improve work efficiency.

\subsection{3 docking colleges and universities to improve farming}

Colleges and universities provide technical guidance to farmers to obtain samples for research to achieve mutual benefits and win-win results. As mentioned earlier, the serious shortage of farmers in farming technologies hinders the development of farmer households and makes the work of eliminating poverty hard. The "peer-to-peer" client enables farmers to receive one-on-one technical guidance to solve the breeding confusion of farmers by building a bridge between rural farmers and veterinarian-related majors and institutions. Through the platform to hold online lectures, to the countryside to preach and timely release of the latest market demand for aquaculture products, so that farmers understand more market demand and dynamic according to market dynamics and timely adjustment of aquaculture structure.

Farmers aspects:

Farmers can issue aquaculture problems through the platform and make online help. When the demand for the same type of diseases in the same urban area on the platform reaches a certain amount, the platform dispatches experts to go to the countryside for treatment and treatment, so as to solve the problem of breeding for farmers.

farmers can make an appointment to the appropriate veterinary experts to the countryside for 
diagnosis and treatment.

University aspects:

colleges and universities through the platform to establish the university independent veterinary breeding disease database, intellectual property owned by colleges and universities. At present, agricultural colleges and universities may face the problem of insufficient sample size, lack of breeding grounds and insufficient research funding. Scientific research workers in colleges and universities may use their farms to breed livestock and poultry, build and expand their sample databases, get on. The database of diseases created by colleges and universities has the right of autonomous use. If the data is not released by the relevant universities, such as commercial sales data, the database will be investigated for legal responsibility so as to ensure the intellectual property rights of the relevant universities.

colleges and universities through the platform for the school students to provide internship and social practice opportunities. Every year a new batch of veterinary majors graduates, and they need enough opportunities to learn in the field to gain practical experience. Although regular formal veterinarians admit these graduates to internships, the actual internship is not satisfactory. Since most veterinarians now serve dogs and cats, pet owners care for their pets. In order to avoid medical disputes and financial losses, hospitals do not allow students to do it themselves. On the contrary, going to the countryside or meeting the needs of students can not only provide more hands-on opportunities for students, but also treat more than dogs and cats. The same schools can also carry out "three countryside" summer social practice activities, encourage students to choose the practice object on the platform so that students practice practical significance.

Colleges and universities provide a certain number of experts and professors for the platform, the platform organizes regular online lectures by integrating resources and professors and professors, and provides a certain degree of rural clinics. To avoid waste of resources, the platform will integrate the needs of farmers diagnosis and treatment, after reaching a certain amount of demand sent medical experts, such as once a week, travel accommodation accommodation by farmers to share, if the government subsidies or the government to bear the cost of farming, breeding Households do not have to spend money.

\subsubsection{Network sales, expand the platform}

Farmers can also purchase the required breeding products through the platform or sell their products online to expand sales channels. The platform for small and medium-sized farmers matchmaking, direct communication companies or restaurants, etc., farmers will be online sales of products online, similar to the current prevalence of Taobao, Jingdong, the main online retail, online sales through the Internet, and provide sales scoring system to evaluate the farmers' products to ensure the overall quality of the platform products. The platform charges a certain fee based on the transaction amount for platform maintenance. Another model is to communicate with farming enterprises to form the current "company + farmers" and "cooperatives + farmers" model. Although these models can solve the technical problems of farmer households to a certain extent, the drawback is that for the purpose of profit-making, the farmers inevitably suffer from the loss of interests of farmers and have no right to speak. In addition, the cultivation plan of large-scale farms is highly refined. If the breach of contract farmers, will bring huge losses to the company. If through the "point to point" electronic platform, both sides can view each other's information according to the database to select partners, effectively avoiding the problems caused by the strength of both parties.

Under the circumstances that the accurate poverty alleviation work is facing a lot of difficulties, I hope that through this innovative thinking, we can improve the existing difficult situation of farmers to get out of poverty. The "platform-to-point" model for building an anti-poverty model has the advantages of high accuracy, high resource integration, and multi-party profitability. The above countermeasures are highly feasible. If the concept of the electronic platform can be effectively implemented, the existing problems such as subjective reluctance of farmers to emerge from poverty in the rural areas, lack of objective cultivation techniques and sales channels, etc. can be 
effectively solved. In addition, through the "point-to-point" electronic platform, mutual benefits of farmers, universities, investors and purchasers can be realized, thereby alleviating the game of interest between farmers and leading enterprises and the government, and thus effectively seeking the maximum for farmers Benefits, and fundamentally promote the effective development of poverty alleviation work.

\section{References}

[1] Fan Hesheng, Tang Huimin. Policy Improvement on Rural Poverty Alleviation and Precise Poverty Alleviation [J] .2017 (1): 45-51

[2] COADY D P, GROSH M, HODDIONTT J. Targeting of transfers in developing countries: review of lessons and experience [M]. World Bank Publications, 2004

[3] Ma Jiehua. Exploration on the Transformation of Rural Poverty and Practical Poverty Alleviation Practices [J]. Journal of Southwest University (Social Science Edition) .2017-9 (43-5)

[4] Liu Meng. Research on New Model of Poverty Alleviation in the Context of "Internet +". China's Market [J] .2017-8 (22): 92-103

[5] Ma Huateng. Proposal to Promote the Economic and Social Innovation and Development in China Driven by "Internet +". China Science and Technology Industry [J] 2016 (3): 38-39 